\title{
Kritik Sosial Politik dalam Lakon Semar Gugat karya Nano Riantiarno
}

\author{
SUMPENO $^{1}$ \\ Jurusan Teater, Fakultas Seni Pertunjukan, Institut Seni Indonesia Yogyakarta
}

\begin{abstract}
Socio-Political Critique in Nano Riantiarno's Semar Gugat. This article discusses social critique of Semar Gugat play script, various symbolism within the play, and socio-historical factors behind the writing of Riantiarno's plays. Semar Gugat is interpreted as a manifestation of Riantiarno's critiques to social, political, economy, and law disparities in Indonesia. Through this play, Riantiarno criticizes the authoritarian, corrupt, and colluded political system of New Order. Semar is a manifestation of grassroots people's struggle against an authoritarian government.
\end{abstract}

Key words: Semar Gugat, semiotic, structuralism

\section{Pendahuluan}

Sekian banyak drama yang telah ditulis dan disadur Riantiarno, tetapi ada sebuah drama yang cukup menarik yakni Semar Gugat. Di dalam Semar Gugat penyampaian masalah kritik sosial terasa halus. Hal ini bisa dipahami sebab penguasa Orde Baru di masa lalu cukup represif terhadap para pejuang demokrasi dan para aktivis yang selalu mengkritik sistem pemerintahan yang ada. Pada masa reformasi, Riantiarno tidak pernah berhenti mengkritisi berbagai penyimpangan sosial, ekonomi, politik, dan hukum melalui karyanya. Hal ini karena berbagai praktik penyimpangan tersebut tetap berlangsung di era reformasi ini.

Dalam Semar Gugat dikisahkan bahwa dalam perkawinannya dengan Arjuna, Srikandi meminta maskawin berupa "pemotongan kuncung (rambut) Semar”. Arjuna meluluskan permintaan itu. Semar merasa terhina dan sangat malu terhadap dunia. Semar pergi ke Kahyangan meminta kepada Batara Guru dan Batara Narada agar wajahnya dikembalikan menjadi tampan seperti sediakala. Kedua penguasa para dewa mengabulkan permintaan Semar. Semar berubah rupa dan nama menjadi Prabu Sanggadonya Lukanurani. Semua keruwetan di Amarta ternyata bersumber dari dewi penguasa jin dan setan bernama Batari
Durga dan Kalika. Durga berhasil menyusup ke dalam badan Srikandi dan berhasil mengobrakabrik Amarta. Yudistira, Bratasena, Nakula, dan Sadewa pergi bertapa meminta pengampunan para dewa karena Semar telah sangat dihina. Semar alias Sanggadonya menantang perang Arjuna dan Srikandi. Ternyata kentut Semar tidak hebat lagi sebab ia telah beralih rupa sebagai Sanggadonya. Sanggadonya meminta kepada para dewa agar jatidirinya sebagai Semar dikembalikan. Tujuannya adalah agar kentutnya bisa sakti untuk mengalahkan Arjuna dan Srikandi.

Apabila diamati secara seksama, munculnya peristiwa-peristiwa sosial dan tindakan-tindakan tokoh cerita yang penuh simbolik itu secara sosiologis berkaitan dengan kondisi sosio-historis masyarakat Indonesia semasa rezim Orde Baru dan Reformasi. Berbagai fakta sosiologis yang terdapat dalam kedua drama karya Riantiarno jelas berkaitan dengan faktor-faktor eksternal di luar teks drama. Dengan demikian, penelusuran tentang berbagai hubungan kritik sosial perlu dilakukan. Bagaimana masalah kritik sosial teks dramaSemar Gugat, apa makna dari berbagai sistem tanda yang terdapat dalam drama tersebut, serta faktor-faktor sosial historis yang menyebabkan lahirnya drama-drama karya Riantiarno.

Alamat korespondensi: Prodi Teater, Institut Seni Indonesia Yogyakarta, jln. Parangtritis Km. 6,5 Sewon, Yogyakarta 55001. Tlp. 0274-375380, e-mail: pakpeno@gmail.com 
Ferdinand de Saussure mengatakan bahwa tanda dalam semiotika memiliki dua aspek, yakni penanda (signifier) yang merupakan konsep atau bentuk tanda yang menandai petanda (signified) yang merupakan maknanya (Noth, 1990: 60). Berdasarkan hubungan antara penanda dengan petandanya, maka tanda dibedakan menjadi tiga macam, yakni ikon, indeks, dan simbol. Menurut Charles Sander Pierce ikon adalah tanda yang penanda dengan petandanya memiliki hubungan kemiripan; indeks adalah tanda yang penanda dan petandanya memiliki hubangan kausalitas; sedangkan tanda adalah penanda dan petandanya ditandai hubungan yang bersifat arbitrair disebut simbol (Noth, 1990: 45).

Berbagai fakta yang ada menunjukkan bahwa sebagian besar tanda bahasa berupa simbol. Dalam hubungannya dengan karya sastra, Preminger, dkk (1974: 981) mengatakan bahwa bahasa merupakan sistem tanda tingkat pertama (first order semiotics), sedangkan sastra merupakan sistem tanda tingkat kedua (second order semiotics). Arti bahasa adalah arti (meaning), sedangkan arti sastra adalah arti dari arti (meaning of meaning) atau makna (significance). Substansi semiotika dalam analisis teks drama adalah untuk memberi makna karya sastra sebab karya drama sebagai teks sastra merupakan sistem tanda yang mempunyai makna. Proses pemaknaan karya drama menurut Culler (1981) disebut sebagai proses perburuan tanda-tanda (the pursuit of sign).

Riffaterre mengemukakan bahwa pemaknaan karya sastra, termasuk drama, merupakan suatu sistem tanda-tanda dengan istilah memproduksi makna tanda-tanda (1982: 23). Dikatakannya bahwa arti (signified) itu tidak terletak "di belakang" penandanya (signifier), melainkan penanda itu merupakan penanda yang menjanjikan sesuatu arti yang harus diusahakan untuk diproduksi oleh pembaca. Karya sastra sebagai struktur tanda merupakan artefak yang belum mempunyai makna sebelum diberi makna oleh pembaca (Teeuw, 1984: 191).

Goldmann (1973: 118-119) menggariskan bahwa dalam perspektif sosiologi seni nonMarxis terdapat empat pemikiran tentang sastra, termasuk drama, yakni: (1) drama bukan sekedar refleksi kenyataan dan kecenderungan kesadaran kolektif, tetapi sebagai puncak koherensi dari kecenderungan-kecenderungan terhadap kesa- daran kelompok tertentu; (2) karya sastra, termasuk drama berhubungan dengan ideologi kolektif, filosofis, dan ideologi; (3) karya sastra berhubungan dengan struktur mental kelompok sosial tertentu; dan (4) kesadaran kolektif bukanlah realitas utama.

Sesuai dengan namanya, strukturalisme genetik memandang karya drama sebagai sebuah struktur yang antar-unsurnya saling berkaitan. Pada prinsipnya strukturaslime genetik memandang karya drama semata-mata merupakan struktur statis dan lahir dengan sendirinya, tetapi merupakan hasil strukturasi dari struktur kategoris pikiran subjek penciptanya yang terbangun akibat interaksi antara subjek itu dengan situasi sosial ekonomi tertentu (Goldmann, 1970: 584).

Pendekatan strukturalisme genetik selalu berusaha mencari perpaduan antara struktur teks dengan konteks sosial karena prinsip pendekatan ini juga mempertimbangkan faktor sosial yang berpengaruh terhadap lahirnya suatu karya drama, mengkaji struktur teksnya yang berkaitan dengan kondisi sosial zamannya. Pendekatan ini menganggap adanya homologi antara struktur teks dengan struktur mental kelompok sosial masyarakat (Goldmann, 1977: 15).

Relasi antara teks dengan konteks sosial tidak bersifat langsung, sebab antara keduanya dimediasi oleh pandangan dunia kreatornya. Goldmann (1981: 112) menyebut pandangan dunia sebagai struktur kategoris yang merupakan kompleks menyeluruh tentang gagasan-gagasan, aspirasiaspirasi, dan perasaan-perasaan yang dihubungkan secara bersama-sama anggota kelompok sosial tertentu, dan mempertentangkannya dengan kelompok sosial lain. Pandangan dunia inilah yang menjadi sumber koherensi struktur teks drama. Oleh karena merupakan hasil interaksi antara subjek kolektif dengan situasi sekitarnya, maka pandangan dunia tidak lahir dengan tiba-tiba. Proses transformasi mentalitas padangan dunia yang berlangsung lama terutama disebabkan oleh kenyataan bahwa pandangan dunia merupakan kesadaran yang mungkin tidak dapat dipahami oleh setiap orang.

\section{Kritik Sosial Semar Gugat}

Dapat dikatakan bahwa kritik sosial selalu mewarnai semua drama Riantiarno. Kenyataan demikian tidak terkecuali dengan drama Semar 
Gugat (untuk selanjutnya disebut SG). Dalam drama ini, kritik sosial ditujukan kepada berbagai pihak seperti rezim Orde Baru, konglomerat yang menjadi kroni penguasa Orde Baru, dan sebagainya.

\section{Kritik terhadap Rezim Orde Baru}

Pada era Orde Baru tidak setiap seniman atau individu berani mengkritik para penguasa Orde Baru. Hal ini terjadi karena absolutnya sistem kekuasaan saat itu. Siapa pun yang berani berbeda pendapat dengan penguasa, bisa berhadapan dengan aparat keamanan. Oleh sebab itu tidak jarang pentas Teater Koma diberhentikan aparat keamanan karena melemparkan kritik-kritik yang pedas terhadap penguasa. Dalam drama Semar Gugat kritik terhadap rezim penguasa Orde Baru yang diungkap Riantiarno misalnya tampak dalam kutipan berikut.

$\begin{aligned} & \text { Durga }: \text { Apa sih yang sudah dilakukan } \\ & \text { Arjuna? } \\ & \text { Kalika } \quad: \text { Ada daftarnya, paduka. Ham } \\ & \text { ba ringkaskan. Ah, ini dia..... }\end{aligned}$

Kritik... Taktik... Politik... Intrik... Licik... Cilik... Sidik... Bidik... Titik..!

Pers.... Press.... Stress.... Beres!.... Tiga Majalah keeek!Tiga pemimpin redaksi ..... keeek! Hari.... Sakti...... mati....! Cekal..... Begal...... Regal.......Bebal. Kontes.... Oles..... Poles..... Protes, Protes, Prote! Waduh, Paduka! Tega deh mereka (Riantiarno, 1995: 47-48).

Dialog antara Durga dengan Kalika di atas, banyak didominasi oleh penggalan kalimat-kalimat atau kata-kata lepas. Kata-kata tersebut dapat diambil kata kuncinya untuk dimaknai, seperti kata "kritik", "politik", "pers", "tiga majalah keeek", "tiga pemimpin redaksi keek", "cekal". Penggalan-penggalan kalimat dan katakata semacam "kritik", "politik", "pers", "tiga majalah keeek", "tiga pemimpin redaksi keek", "cekal" merupakan ringkasan dari isu besar yang terjadi selama Orde Baru. Rezim penguasa Orde Baru yang otoriter pada saat itu cenderung represif terhadap kebebasan pers bahkan tidak ada kebebasan pers. Setiap media massa yang berani mengkritik kebijakan penguasa, media itu dicekal pemimpin redaksinya atau dibrediel media penerbitannya. Inilah sesungguhnya kritik yang disampaikan Riantiarno kepada rezim penguasa saat itu. Oleh karena represifnya rezim yang berkuasa saat itu, kritik yang disampaikan tidak bersifat langsung atau verbal, akan tetapi hanya melalui penggalan kalimat-kalimat di atas. Sekalipun demikian, masyarakat dapat memahami dan mengerti makna kritik tersebut.

Kondisi sosial masyarakat pada era Orde Baru yang sangat kapitalistik, merajalelanya kemiskinan, bobroknya sistem pendidikan, tidak diakuinya hak-hak azazi masyarakat dan semacamnya tidak lepas dari kritikan Riantiarno. Melalui kritikannya tampak bahwa betapa pengarang drama ini cukup berani terhadap rezim Orde Baru. Hampir semua sisi kehidupan tak lepas dari penilaian Riantiarno. Sesuatu yang disampaikan Riantiarno di atas tidaklah berlebihan, sebab memang kondisi saat itu benar-benar mengalami degradasi nilai-nilai dalam berbagai bidang kehidupan.

\section{Kritik terhadap Pejabat dan Konglomerat}

Para pejabat dan konglemerat tak lepas dari kritikan Riantiarno. Melalui dialog antara Semar dengan Gareng seperti di bawah ini :

Semar : Sia-sia kalau kamu tidak merestui. Untuk apa semua perjuangan ini? Untuk Siapa?

Gareng : Ya untuk anak, bini, keponakan, cucu, cicit, canggah, wareng, udegudeg, gantung siwur. Pokok kata untuk lebih dari 7 turunan. Kalau bisa. Sekarang bini ogah. Ya, tidak apa-apa. Kan masih ada famili lain. Misal, saya dan Petruk. Cukup itu. Kemudian, kalau Bagong pulang, dia bisa langsung bergabung. Hasil perjuangan yang tidak dinikmati, jelas mubazir. Ini kan anugerah? (Riantiarno, 1995: 74)

Kutipan di atas memberikan gambaran yang kritis tentang sikap pengarang terhadap pejabat dan konglomerat. Para pejabat bila menduduki jabatan tertentu cenderung korupsi. Hasil korupsi bisa tidak hanya untuk dirinya tetapi juga anak keturunannya. Begitu pula para konglomerat, 
mereka menjalin kolusi dengan para pejabat untuk mendapat fasilitas tertentu seperti monopoli dagang, pembebasan pajak, fasilitas kredit tanpa agunan dan sebagainya. Tindakan demikian jelas bagian dari korupsi itu sendiri. Perbuatan melawan hukum semacam itu terbukti membebani perekonomian nasional. Puncaknya adalah saat terjadi krisis ekonomi pada tahun 1998 yang ditandai dengan lengsernya penguasa Orde Baru dan membengkaknya hutang luar negeri akibat menanggung hutang para konglomerat. Krisis moneter menyebabkan perekonomian nasional ambruk sehingga jumlah penduduk miskin semakin bertambah banyak.

Bisnis para konglomerat yang merambah ke berbagai bidang usaha, tak lepas dari kritikan pengarang. Digambarkan bahwa semua bisnis yang terkait dengan "jalan raya" diborong habis para konglomerat. Hal ini seperti diucapkan Petruk, "Dimana mesti mencarinya Mak? Semua jalan sudah diborong habis. Tol, arteri, bolevar-ddh, haiwey, semua sudah ada pemborongnya. Kita mah paling kebagian gang, buntu lagi. Sebab gang yang tidak buntu juga jelas sudah jadi proyek, ada dip ada dupnya. Rezeki for the lower people mah sudah sangat mampet, Mak" (Riantiarno, 1995: 34). Hampir tak ada peluang bagi rakyat kecil untuk berkiprah secara leluasa dalam perekonomian nasional, sebab sudah banyak sektor dikuasai para kongmerat dan keluarga pejabat yang berbisnis.

Riantiarno tidak hanya mengkritik rezim Orde Baru dan para Konglomeret. Ia juga mengkritik para mahasiswa. Para mahasiswa yang seringkali melakukan demonstrasi dianggap Riantiarno tidak efektif. Cara mereka demo dengan turun ke jalan, bawa spanduk, poster, pamplet dianggap sekedar sebagai sport politik atau mainan anakanak muda (Riantiarno, 1995: 38). Riantiarno menganggap cara demikian tidak tepat sasaran, ongkosnya mahal, mudah ditunggangi dan salahsalah digebuki para polisi.

\section{Pandangan Dunia Pengarang}

Pandangan dunia bukanlah pandangan dunia kolektif kelompok atau kelas sosial tertentu dalam interaksinya dengan dunia. Pandangan dunia merupakan konsep abstrak yang menyatukan suatu kelompok tertentu dan membedakannya dengan kelompok atau kelas sosial lainnya. Menurut Goldmann (1970: 538) sebagai fakta kemanusiaan, karya drama merupakan respon dan subjek terhadap situasi di sekitarnya, dan usaha untuk memodifikasi situasi yang ada agar cocok dengan aspirasi-aspirasinya. Goldmann juga mengatakan bahwa karya sastra merupakan hasil usaha manusia untuk mencapai keseimbangan yang lebih baik dalam hubungannya dengan dunia di sekitarnya. Dalam karya sastra, ada pada sifat tematiknya karena karya sastra merupakan strukturasi pandangan dunia pengarang dan kelompok sosialnya. Jadi, pandangan dunia pengarang yang dipengaruhi kelompok sosialnya akan mengental sebagai pemersatu dan menjiwai struktur karya sastra sebagai keseluruhan. Oleh karena itu, untuk memudahkan analisis perlu dikemukakan kelompok sosial pengarang dan pandangan dunianya dalam drama Semar Gugat.

Berdasarkan analisis struktur tema lakon Semar Gugat telah tersingkapkan bahwa permasalahan yang digarap pengarang dalam lakon tersebut berkisar pada kecenderungan perilaku manusia modern yang mengedepankan ambisi pribadi, individualis, dan lebih mementingkan nilai-nilai fisik serta materialisme sehingga meninggalkan nilai-nilai kerokhanian. Permasalahan tersebut dikongkritkan melalui tokoh Semar. Para tokoh atasan seperti Arjuna dan Srikandi juga menunjukkan kecenderungan yang sama. Semua tokoh itu terlibat dalam perburuan yang sama, yakni nilai-nilai lahiriah (materi) dan bentuk pemuas dunia lainnya.

Pada satu sisi, Semar ingin mempertahankan statusnya sebagai manusia setengah dewa, namun ia tidak tahan menghadapi hinaan Srikandi dan Arjuna. Semar menggugat para dewa agar ia diberikan wajah yang tampan dan takhta kekuasaan sebagai raja. Arjuna pun meninggalkan jiwa kesatrianya. Terbukti dengan mudah tergelincir dengan pesona kecantikan Srikandi yang telah dirasuki Durga. Memang dampak negatif modernisasi belum separah di negara-negara Barat. Meski demikian bukan berarti gejala-gejala yang mengarah ke sana belum kelihatan. Misalnya, mulai tumbuhnya dekadensi moral dalam masyarakat, kecenderungan manusia berpikir rasional dan pragmatis, kecenderungan manusia mengagungagungkan nilai-nilai duniawi serta semakin terlihat rapuhnya solidaritas sosial yang bisa berlanjut pada mengecilnya nilai-nilai kemanusiaan. 
Kekhawatiran seperti di atas bukan tanpa alasan. Saat Indonesia telah berada di abad ke21, perekonomian nasional banyak dipengaruhi perekonomian internasional (global) yang cenderung sangat kapitalistik. Pada masa tersebut perekonomian Indonesia banyak ditopang oleh sektor perindustrian. Pada sisi lain, ilmu pengetahuan dan teknologi akan semakin banyak termanifestasikan dalam banyak sektor kehidupan. Abad ke-21 diharapkan Indonesia menjadi negara industri maju yang mampu berswasembada melaksanakan pembangunan seperti halnya Malaysia, China, Singapura dan lain-lain.

Agaknya Nano Riantiarno memandang situasi sosial semacam itu sebagai sesuatu yang tidak normal, sehingga harus diluruskan. Tampaknya pandangan dunia Riantiarno dan kelompok sosialnya, seperti para cendekiawan, seniman, intelektual dan sebagainya tentang proses modernisasi yang lebih mengedepankan keberhasilan material atau nilainilai material, bukan nilai-nilai spiritual menjadi penggerak ide karya-karyanya. Sebagai seorang intelektual yang senantiasa terlibat atau menjadi saksi setiap gerak nadi kondisi sosial politik bangsanya, maka lahirnya drama-drama yang mengangkat ide-ide yang menjadi kegelisahan masyarakat tidaklah aneh.

Revolusi sosial, politik, ekonomi, dan karyakarya kultural yang besar merupakan fakta sosial. Seorang individu dengan dorongan libidonya tak akan menciptakannya, yang dapat menciptakannya hanya subjek transindividual (Goldmann, 1981: 97). Subjek kolektif merupakan subjek yang bisa mengatasi individu, yang di dalamnya hanya merupakan bagian dari suatu kolektivitas. Relevansinya dengan karya seni modern, subjek karya itu bersumber pada kelompok sosial yang kecil yang masih berpikir tentang nilainilai otentik. Kelompok inilah yang termasuk kelompok sosial pengarang yang di dalamnya juga tercakup seniman, filosof, teologian dan sebagainya (Goldmann, 1977: 11).

Dalam perpektif Goldmann, Nano Riantiarno merupakan subjek dari karya-karyanya. Sebagai dramawan, Riantiarno masih berpikir tentang nilainilai otentik bagi perbaikan tatanan kehidupan masyarakat. Nilai-nilai otentik itu secara implisit tampak dari nilai-nilai yang dianut Semar setelah menyadari kekeliruannya beralih rupa menjadi Prabu Sanggado, yakni ingin kembali menjadi manusia yang bijaksana, dan tidak mengagungagungkan nilai-nilai materialisme. Pada saat drama SG ditulis tahun 90-an, perjuangan untuk mendapatkan nilai-nilai otentik tidak hanya menjadi obsesi Riantiarno, tetapi juga kelompok sosial pengarang yang lain seperti cendekiawan maupun seniman.

Lakon Semar Gugat penuh dengan konflikkonflik sosial antar tokoh yang dilatarbelakangi hasrat memburu nafsu duniawi sebanyaksebanyaknya, khususnya seperti dilakukan Arjuna, Srikandi, Durga, Kalika dan Semar. Mereka adalah manusia-manusia yang menjadi korban suatu modernisasi yang menjadikan nilai-nilal materi sebagai tujuan hidupnya. Sementara itu, tokoh Semar sekalipun pernah terjebak dalam nilai-nilai materialisme, tetapi akhirnya menyadari kekeliruannya dan berusaha kembali ke jalan yang benar. Bisa jadi sosok tokoh yang terlalu mengabdikan hidupnya nafsu duniawi semacam Arjuna, Srikandi dan lain-lain secara mimesis juga terjadi dalam kehidupan nyata.

Berbagai fenomena sosial di atas itulah yang dimungkinkan menjadi penyebab lahirnya Semar Gugat. Disadari atau tidak oleh pengarang, kondisi sosial yang terjadi di sekitar kehidupannya telah berpengaruh terhadap proses kreatifnya (Nur Sahid, 2002: 79). Pada hakekatnya kecenderungan perilaku manusia modern yang mencampakkan nilai-nilai keilahian dan sebaliknya, ia hanya meyakini nilai-nilai material semata-mata dapat diidentikkan dengan Arjuna dan Srikandi.

\section{Semiotika Semar Gugat}

Pada uraian di atas pembicaraan dipusatkan pada analisis struktur tema drama SG. Analisis struktural tersebut memang memberikan gambaran yang jelas tentang tema cerita. Akan tetapi anasir-anasir yang terkait dengan masalah kemanusiaan dan kebudayaan belum disentuh dengan tuntas. Bahasa dalam SG tidak hanya dilihat sebagai suatu media ekspresi untuk mendapatkan efek estetiknya, tetapi juga dilihat keterkaitannya dengan faktor-faktor eksterinsik. Sehubungan dengan itu, SG perlu dikaji lebih jauh tidak hanya secara struktural genetik, melainkan juga secara semiotika. Pendekatan semiotika terhadap SG ini proses kerjanya menggabungkan unsur intrinsik dan eksterinsiknya. 


\section{Simbolisasi Kekuasaan}

Dalam analisis struktur SG telah diungkapkan bahwa tokoh Srikandi memiliki kekuasaan yang luar biasa besarnya. Tokoh Arjuna sebagai calon suaminya tak pernah bisa menolak perintah atau permintaan Srikandi. Salah satu perintah yang membuat geger Amarta adalah saat ia meminta maskawin pemotongan kuncung Semar di hadapan para tamu. Arjuna seolah-olah selalu dalam cengkeraman Srikandi. Dalam kerangka semiotika teks tokoh Srikandi menduduki fungsinya sebagai penanda (signifier). Tokoh Srikandi adalah simbolisasi dari suatu kekuasaan besar yang menentukan jalan hidup bagi Arjuna. Arjuna tidak pernah bisa menolak terhadap setiap permintaan Srikandi. Melalui kasus di atas, tampak bahwa sebagai laki-laki Arjuna termasuk laki-laki yang lemah. Ia tidak memiliki pendirian yang tegas. Ia menurut saja terhadap permintaan Srikandi, sekalipun permintaan itu akhirnya mencelakakan kehidupan orang lain. Terbukti sejak awal sampai akhir cerita tindakan pasangan suami istri yang memotong kuncung Semar sangat berpengaruh kepada kehidupan Semar sehingga terlunta-lunta.

\section{Simbolisasi Kaum Tertindas}

Dalam kaitannya dengan makna kekuasaan, tokoh Semar dapat dikatakan sebagai tokoh yang paling tidak memiliki kekuasaan. Apabila Srikandi tampak begitu berkuasa, maka Semar justru sebaliknya. Semar adalah simbolisasi dari manusia tertindas yang tidak memiliki kekuasaan ekonomi, sosial, dan sebagainya. Dalam sepanjang hidupnya, ia banyak ditentukan oleh pengaruh pihak lain seperti Srikandi dan Arjuna. Semar dipotong kuncungnya di depan perjamuan pernikahan Arjuna dan Srikandi. Padahal Semar adalah figur yang dihormati oleh para Pandhawa bahkan para dewa pun menghormatinya. Batara Guru dan Narada tidak dapat menolak desakan Semar agar merubah wajahnya menjadi sosok kesatria yang tampan.

\section{Simbolisasi Hancurnya Nilai-Nilai Reli- gius}

Tokoh Semar sebagai penanda juga meng andung makna sebagai perlambang manusiamanusia modern yang senantiasa mendewadewakan kekuasaan dan nilai-nilai material, sehingga jauh dari nilai-nilai keilahian. Hal ini tampak jelas ketika ia harus melabrak Batara Guru dan Narada di Kahyangan agar merubah bentuk wajah dan fisiknya. Dalam konteks ini, kesederhanaan, kepasrahan, kesabaran dan kearifan yang menjadi karakter utama Semar seolah-olah hilang begitu saja. Sebaliknya, ia justru menjadi manusia pendendam. Ia ingin berkuasa sebagai raja. Ia ingin memiliki wajah tampan seperti Arjuna. Tujuannya tidak lain adalah untuk meninggikan derajat, martabat dan status sosial. Cara semacam ini diharapkan akan diperlakukan secara terhormat oleh orang lain. Ia tidak ingin dipermalukan lagi seperti saat kuncungnya dipotong oleh Arjuna. Akan tetapi hasilnya ternyata sia-sia. Sekalipun Semar telah berkuasa di Simpang Buwana Nuranitis Asri namun ia tidak tampil sebagai raja yang berwibawa, berkharisma dan dihormati oleh para raja yang lain. Malahan ketika berperang melawan Durga ia pun kalah. Terbukti kentutnya yang dahulu sakti tak mampu lagi mengusir Durga.

Hilangnya rasa percaya diri Semar akibat dipotong kuncungnya adalah manifestasi dari runtuhnya nilai-nilai religiusitas pada diri Semar. Ia yang semula pasrah, sabar, arif dan senantiasa mempercayai takdir Illahi kini berubah sebaliknya. Sejak dihina Arjuna dan Sarikandi. Semar menjadi manusia yang lebih pragmatis. Semar tergoda ingin berkuasa dan memiliki wajah yang tampan. Dalam kerangka semiotika, Semar menduduki fungsi penanda dari runtuhnya nilainilai religiusitas.

\section{Penutup}

Lakon Semar Gugat memiliki tema bahwa kebahagiaan hidup manusia di dunia tidak selamanya ditentukan oleh keindahan fisik (tubuh) dan tahta kekuasaan yang dimilikinya, namun juga oleh nilai-nilai rokhaniah yang bernafaskan Ketuhanan. Pengarang merealisasi tema tersebut melalui tokoh utama Semar. Sikap hidup Semar yang telah bergeser dari manusia setengah dewa yang arif, bijaksana, dan sabar menjadi manusia yang mengedepankan nilai-nila materialisme (keindahan fisik dan tahta kerajaan) ternyata tidak membuat hidupnya menjadi bahagia.

Lakon Semar Gugat dapat ditafsirkan sebagai manifestasi pandangan kritis Riantiarno terhadap 
berbagai kepincangan sosial, politik, ekonomi, dan hukum di negeri ini. Pengarang mengkritik sistem politik Orde baru yang otoriter, korup dan penuh kolusi. Hal ini ditandai dengan berontaknya rakyat kecil yang disimbolkan tokoh Semar akibat kesewenang-wenangan majikan (Arjuna dan Srikandi) yang akan memotong kuncung rambutnya untuk mas kawin. Sebagai rakyat kecil Semar merasa terhina, sehingga ia melawan Arjuna dan Srikandi. Tindakan Arjuna dan Srikandi yang akan memotong kuncung Semar merupakan simbol ketidakpekaan penguasa terhadap rakyat yang selama ini telah secara jujur mengabdi kepada mereka.

\section{Kepustakaan}

Alex, Preminger, dkk. 1974. "The Semiotics" dalam Encyclopedia of Poetry and Poetics. Princeton: Princeton University Press,

Culler, Jonathan. 1981. The Pursuit of Sign: Semiotics, Literature, Deconstructions. London: Routledge \& Kegan Paul.

Damono, Sapardi Djoko. 1983. Kesusasteraan Indonesia Modern. Jakarta: Gramedia.

Faruk. 1994. Pengantar Sosiologi Sastra. Yogyakarta: Pustaka Pelajar.

Goldmann, Lucien. 1970. "The Sociology of Literature: Status Problem of Method", dalam The Sociology of Art and Literature. New York: Praeger Publisher.
1977. Towards a Sociology of Novel. London: Tavistock Publication Limited.

. 1981. Method in Sociology of Literature. Oxford: Blackwell Publisher

Junus, Umar. 1986. Sosiologi Sastra: Sebuab Pengantar. Kuala Lumpur: Dewan Bahasa dan Pustaka, Kementerian Pelajaran Malaysia.

Meslawati, Elok Diah. 2001. "Kesaksian Nano Riantiarno", Kompas, 2 Mei.

Noth, Winfried. 1990. Handbook of Semiotics. Bloomington: Indiana University Press.

Riantiarno, Nano. 1992. "Teater dan Masyarakat Teater Koma", dalam Seni Jurnal Penelitian dan Penciptaan Seni. No. II/04, Oktober.

1995. Semar Gugat. Yogyakarta: Bentang Budaya

1999. Opera Ikan Asin. disadur dari The Threepenny Opera karya Bertolt Brecht. Jakarta: Pustaka Jaya.

Riffaterre. 1982. Semiotics of Poetry. Bloomington:. Indiana University Press.

Sahid, Nur. 2002. "Kritik Sosial dalam Beberapa Drama Karya Arifin C. Noer: Sebuah Tinjauan Semiotika dan Sosiologi Sastra". Laporan Penelitian. Jakarta: DP2M Dikti.

Teeuw. 1984. Sastra dan Ilmu Sastra: Pengantar Teori Sastra. Jakarta: Pustaka Jaya. 